\title{
Alcoholic Dementia
}

\author{
Maurice Victor
}

\begin{abstract}
At least four distinct cerebral diseases - Wernicke-Korsakoff, Marchiafava-Bignami, pellagrous encephalopathy, and acquired hepatocerebral degeneration - have a close association with chronic alcoholism. Each is characterized by a distinctive pathologic change and a reasonably wellestablished pathogenesis; in each the role of alcohol in the causation is secondary. The question posed in this review is whether there is, in addition to the established types of dementia associated with alcoholism, a persistent dementia attributable to the direct toxic effects of alcohol on the brain - i.e., a primary alcoholic dementia. The clinical, psychologic, radiologic, and pathologic evidence bearing on this question is critically reviewed. None of the evidence permits the clear delineation of such an entity. The most serious flaw in the argument for a primary alcoholic dementia is that it lacks a distinctive, well-defined pathology, and it must remain ambiguous until such time as its morphologic basis is established.
\end{abstract}

Résumé: La démence alcoolique: une revue critique. Au moins quatre maladies cérébrales distinctes - le Wernicke-Korsakoff, le Marchiafava-Bignami, l'encéphalopathie de la pellagre, la dégénérescence hépatocérébrale acquise - ont une association étroite avec l'alcoolisme chronique. Chacune est caractérisée par des changements anatomopathologiques distincts et une pathogenèse bien établie. Le rôle de l'acool est secondaire dans chacune. Dans cette revue, nous posons la question suivante: en plus des types de démence reconnus comme étant associés à l'alcoolisme, y a-t-il une démence persistante attribuable aux effects toxiques directs de l'alcool sur le cerveau, i.e., une démence alcoolique primaire? Nous revoyons de façon critique les données cliniques, psychologiques, radiologiques et anatomopathologiques reliées à cette question. Aucune observation ne permet de définir clairement une telle entité. La lacune la plus sérieuse vient du fait qu'il n'existe pas de lésion anatomopathologique distinctive. La situation demeurera ambiguë tant que ses assises morphologiques ne seront pas établies.

Can. J. Neurol. Sci. 1994; 21: 88-99

That the long-continued abuse of alcohol may lead to a deterioration of intellect, behavior, and personality has been appreciated for many years. Maudsley (1879), ${ }^{1}$ in his book "The Pathology of Mind", commented upon the weak will-power, blunting of moral sense, and childish intellect of the alcoholic and likened his mental state to that observed in the late stages of senile dementia. Lawson, ${ }^{2}$ writing in the first volume of Brain (in 1878) attributed both memory defects and a general decay of intellectual function to alcoholism. And Bevan Lewis ${ }^{3}$ in 1889 , remarked upon impairments of attention, judgment, and memory as well as deterioration of the finer sensibilities and moral nature of alcoholics. Thus an association between alcoholism and intellectual decay was appreciated early on; however, the nature of this association was quite unclear and seemed to excite little curiosity.

The clinical picture that emerged from these early writings (and many later ones) was far from uniform, and came to be designated by a variety of terms such as alcoholic deteriorated state, organic or chronic brain syndrome due to alcohol, and alcoholic pseudoparesis. From the perspective of psychiatrists working in mental hospitals, alcoholism, along with senility and cerebral arteriosclerosis, were for many years the most frequently designated causes of dementia. Implicit in the diagnosis of alcoholic dementia was the belief that there was a global impairment of intellect attributable to the direct effects of alcohol on the brain - a notion that survives to the present day. In fact, in the last decade or two, there has been a renewed avowal of this idea. Large numbers of alcoholics have been investigated by brain imaging techniques, psychologic testing, and other methods and repeated attempts have been made, on the basis of these investigations, to endow alcoholic dementia with the attributes of a clinical-anatomic entity.

The purpose of this article is to analyze recent writings on this subject and to determine whether or not there is indeed sound medical evidence - clinical, pathologic, or radiologic that permits the delineation of a primary alcoholic dementia, i.e., a uniform chronic mental syndrome attributable to the direct toxic effects of alcohol upon cerebral neurons. In pursuing this analysis, it is important to be mindful of the several well-delineated secondary "alcoholic" dementias - i.e., dementias that occur predominantly (but not exclusively) in alcoholics and are attributable not to alcohol per se but to some other factor(s),

From the Department of Medicine (Neurology). Dartmouth Medical School, Hanover, New Hampshire, and the Veterans Affairs Medical Center, White River Junction, Vermont.

RECEIVED OCTOBER 7, 1993. ACCEPTED IN FINAL FORM JANUARY 10, 1994

Dr. Victor was the Richardson Lecturer at the Canadian Congress of Neurological Sciences, June 1992, Winnipeg.

Reprint requests to: Maurice Victor, M.D., VA Medical Center, White River Junction, VT U.S.A. 05009 
engendered by alcoholism. A detailed account of these secondary dementias cannot be undertaken here, but certain aspects need to be considered, particularly those bearing directly on the subject under discussion.

\section{Secondary Alcoholic Dementias}

\section{The Wernicke-Korsakoff Syndrome}

The first meaningful advance in our understanding of the alcoholic mental disorders came with Wernicke' $s^{4}$ discovery, in 1881 , of an acute neurologic disorder, characterized clinically by ophthalmoplegia, ataxia and a confusional state and pathologically by hemorrhagic lesions in the walls of the third and fourth ventricles and aqueduct of Sylvius ("polio-encephalitis hemorrhagica superioris"). In 1887, the Russian psychiatrist S.S. Korsakoff gave the first comprehensive description of a unique mental disturbance in alcoholics (and non-alcoholics) characterized by a predominant affection of retentive memory and a frequent but not invariable association with polyneuropathy (see Victor and Yakovlev). ${ }^{5}$ Interestingly, neither Wernicke nor Korsakoff was aware of the close relationship of these disorders to one another. This was first suspected on clinical grounds by Murawieff ${ }^{6}$ and Bonhoeffer, ${ }^{7}$ but it was Gamper, ${ }^{8}$ in 1928, who made the astute observation that Korsakoff psychosis and the confusional state attendant upon Wernicke disease had a similar if not identical pathologic anatomy in the walls of the third and fourth ventricles and aqueduct of Sylvius. This relationship was later affirmed by Malamud and Skillicorn ${ }^{9}$ and by Victor et al., ${ }^{10}$ whose nutritional, clinical, and neuropathologic studies indicated that the Korsakoff amnesic state is simply the chronic psychologic residual of Wernicke encephalopathy.

Analysis of a large number of anatomically verified cases of the Wernicke-Korsakoff syndrome, as we have chosen to call it, disclosed a number of interesting clinicopathologic details, the most important of which are (1) that the Korsakoff amnesic state, instead of emerging as the apathetic-confusional state of Wernicke disease subsides, sometimes develops insidiously, without evident ocular and ataxic signs; (2) that some chronic forms of the amnesic syndrome, without evidence of confabulation or ocular or ataxic signs, may not be recognized as Korsakoff psychosis by clinicians (such cases have often been called chronic alcoholic deterioration); and (3) that many cases of the Wernicke-Korsakoff syndrome are discovered upon postmortem examination, without having been recognized as such during life. The latter finding has been repeatedly affirmed by neuropathologists.

Uniformly, the lesions of Wernicke-Korsakoff syndrome have proved to be in the mammillary bodies, the medial thalamic nuclei, the periaqueductal region, and the tegmentum of pons and medulla. The presence of a co-existent cerebral cortical lesion has remained uncertain, however. In addition to the brainstem and diencephalic lesions, one-quarter of the cases in our series showed a mild to moderate degree of ventricular enlargement and sulcal widening, particularly in the frontal regions. More pertinent is the fact that three-quarters of the cases showed no such changes. Moreover, in cases that did show enlargement of ventricles and widening of sulci, careful microscopic study of the cerebral cortex disclosed no definite neuronal loss or gliosis. Others, however, particularly Courville ${ }^{11}$ and Carmichael and Stern, ${ }^{12}$ described cerebral cortical changes such as neuronal swelling and pyknosis, chromatolysis, and lipofuscinosis, which we consider to be insignificant or artefactual, or, in the cases of Carmichael and Stern, to be characteristic of pellagra. Interestingly, these writers (and others subsequently) concluded that the lesions of Korsakoff psychosis were confined to the cerebral cortex; they overlooked the diencephalic and brainstem lesions altogether. More modern writers, particularly those unskilled in neuropathology, continue to refer to these lesions in the cortex as valid findings, not appreciating that the morphologic basis of the dilated ventricles and widened sulci in alcoholics, now readily visualized in CT scans, has never been ascertained.

Numerous clinical studies have clearly established that the Wernicke-Korsakoff syndrome, the most common and clearly delineated type of dementia in alcoholics, occurs also in nonalcoholics; that some instances of the Korsakoff amnesic state in alcoholics are not attended by other signs of Wernicke disease and polyneuropathy; and that the cause of the syndrome in alcoholics is a nutritional deficiency, specifically of thiamine, and not a direct effect of alcohol.

The significance of the aforementioned features of the Korsakoff syndrome vis-a-vis the matter of primary alcoholic dementia will be elaborated further on, in the discussion of the latter disorder.

\section{The Cerebral Manifestations of Pellagra}

During the period in which the Wernicke-Korsakoff syndrome was being identified as an important cause of dementia, a pellagrous form of mental disorder also came to be recognized. In the early part of this century, pellagra attained epidemic proportions in the United States, particularly in the southern states and among alcoholics in large urban centers. Since 1940, the prevalence of pellagra has diminished greatly, attributable, no doubt, to the general practice of fortifying bread and cereals with niacin. Nevertheless, significant numbers of cases are still being observed world-wide, particularly in the alcoholic population. ${ }^{13-16,16 \mathrm{a}}$

The entity of alcoholic pellagra was discredited many years ago by Spies and DeWolfe, ${ }^{17}$ who demonstrated that alcoholic pellagra and endemic pellagra are identical and that the pathogenic role of alcohol is simply one of substituting drink for food. This is now the prevailing view. The cutaneous, gastrointestinal, and neurasthenic symptoms of pellagra are due to a deficiency of either nicotinic acid or of its amino acid precursor tryptophan..$^{18}$ These manifestations respond to the administration of niacin and tryptophan, whereas the neurologic disturbances do not, probably because the latter are due to a deficiency of pyridoxine ${ }^{19,20}$ rather than of niacin and tryptophan.

Clinical Features The mental symptoms of pellagra are less well defined than those of the Wernicke-Korsakoff syndrome. The early symptoms - irritability, depressed mood, fatigue, anorexia, insomnia, inattentiveness and inability to concentrate and to sustain any physical or mental effort - are suggestive of neurasthenia or a depressive illness. Only when confusion, hallucinosis, paranoid ideation, spastic weakness of the limbs with lively reflexes (unless there is a concomitant polyneuropathy), and Babinski signs are added to the clinical picture does the pellagrous nature of the encephalopathy become definite. The early encephalopathic symptoms respond to the administration of niacin and a nutritious diet. Whether or not certain of the cerebral symptoms, if untreated for some weeks, become irreversible, 
leaving in their wake a mild dementia, has not been firmly established. At least this is what one discerns in the writings of authorities such as Still;21 some of the patients to which he refers also had Wernicke-Korsakoff disease and others were patients with psychoses of manic-depressive of schizophrenic type, in whom the pellagra was secondary.

Under the title of nicotinic acid deficiency encephalopathy, Jolliffe and his colleagues ${ }^{22}$ described an acute and frequently fatal disorder among the many alcoholic patients at the Bellevue Hospital, in New York City. The syndrome as observed by these authors was characterized by "clouding of consciousness, cogwheel rigidities of the extremities, and uncontrollable grasping and sucking reflexes". The clinical details of this illness were not fully presented and postmortem findings were not mentioned. Some of the patients had Wernicke-Korsakoff disease and most of them had polyneuropathy; only a minority had pellagrous skin and mucous membrane lesions. Little or no improvement could be discerned in response to administration of thiamine, but in a group of 22 patients who were given nicotinic acid, 15 were said to recover rapidly (and 7 died). Cleckley and his colleagues ${ }^{23}$ had previously commented on the salutary effects of nicotinic acid on the unresponsive state of elderly undernourished patients. Spillane ${ }^{24}$ also drew attention to certain stuporous and psychotic states in malnourished individuals which, because of an apparent response to nicotinic acid, he identified with the nicotinic acid deficiency encephalopathy of Jolliffe et al. ${ }^{22}$ More recently, Serdaru and colleagues ${ }^{14}$ retrospectively reviewed the clinical records of 22 chronic alcoholic patients in whom postmortem examination had disclosed the cerebral changes of pellagra. Prominent clinical features were confusion, clouding of consciousness, "gegenhalten", and myoclonic jerks. These symptoms were thought to be identical with those of the nicotinic acid deficiency encephalopathy of Jolliffe et al. ${ }^{22}$ and were attributed to pellagra ("alcoholic pellagra encephalopathy"). Such a conclusion hardly seems justified, insofar as the pathologic changes of Marchiafava-Bignami disease were present in eight of the 22 cases, Wernicke-Korsakoff disease in four cases, and both of these disorders in yet another case.

To summarize, the status of nicotinic acid deficiency encephalopathy and its relation to pellagra remain uncertain. We have not been able to find any convincing examples of such a nicotinic acid-responsive syndrome despite the examination of large numbers of undernourished patients in the alcoholic populations of Boston and Cleveland.

Pathologic Findings The cerebral pathology of pellagra is most readily discerned in the large cells of the motor cortex, the cells of Betz, although the same changes occur to a lesser extent in the smaller pyramidal cells of the cortex, the large cells of the basal ganglia, the cells of the cranial motor and dentate nuclei, and the anterior horn cells of the spinal cord. The affected cells appear swollen and rounded, with eccentric nuclei and loss of the Nissl particles. Originally, these changes were designated by Adolph Meyer ${ }^{25}$ as "central neuritis"; frequently, they are referred to as "axonal reaction" because of their similarity to the changes that occur in the anterior horn cells when their axons are severed. Whether the central neuritis of pellagra is secondary to an injury of the axons of the motor cells or represents a primary cytolytic degeneration of these cells is still not entirely certain; the latter is much more probable.

\section{Marchiafava-Bignami Disease (Primary Degeneration of the Corpus Callosum)}

This is a rare complication of alcoholism, readily defined by its unique pathologic change - a degeneration of the corpus callosum, particularly its middle layer, and the anterior commissure. Described originally by Marchiafava and Bignami ${ }^{26}$ in wine-drinking Italians, it was subsequently observed in many parts of the world and in association with abuse of all types of beverage alcohol. Whether due to some metabolic abnormality induced by alcohol or to the alcohol itself has still not been settled to everyone's satisfaction; the evidence strongly favors the former possibility.

Clinical Features Practically all the reported patients have been inveterate drinkers, ranging in age from 45 to 60 years, and most are men; often they are malnourished and some have cirrhosis of the liver. Some patients have presented in a state of terminal stupor or coma and others with manifestations of chronic inebriation and alcohol withdrawal. In yet another group, a slowly progressive dementia has been described; dysarthria, slowing and unsteadiness of movement, transient sphincteric incontinence, hemiparesis, and apractic or aphasic disorders were superimposed. In two patients who came to our attention, the clinical manifestations were essentially those of bilateral frontal lobe disorder - motor and mental slowness, apathy, prominent grasping and sucking reflexes, paratonia (gegenhalten), sphincteric incontinence, and a slow, hesitant, wide-based gait.

In view of the variability of the clinical picture, the diagnosis of Marchiafava-Bignami disease is understandably difficult. In fact, the diagnosis is rarely made during life. Chronic alcoholics, who develop a frontal lobe syndrome or a symptom complex that points to a diagnosis of Aizheimer disease or frontal-corpus callosum tumor, but in whom the symptoms remit, should be suspected of having Marchiafava-Bignami disease. CT scans and MRI will undoubtedly prove helpful in identifying the lesion in such patients.

With abstinence and nutritious diet, there may be improvement, but the patient ususally remains in a demented state similar to that seen in frontal lobe-corpus callosum disease of whatever type. One of the patients described by Castaigne et al. ${ }^{27}$ survived as a dement for 10 years.

Pathologic Features The destruction of myelinated fibers in the corpus callosum (particularly the central lamina of the genu) and anterior commissure is the typical finding. Exceptionally, the lesions extend laterally into the centrum semi-ovale and in a few instances the middle cerebellar peduncles have been involved. Many of the reported cases, as first pointed out by Jéquier and Wildi, ${ }^{28}$ have had cortical lesions of a special type; neurons in the third layer of the frontal and temporal lobe cortices had disappeared and were replaced by a fibrous gliosis, presumably secondary to interruption of callosal fibers. ${ }^{28 a} \mathrm{~A}$ similar lesion has been observed in some patients with chronic hepatocerebral disease. Morel, ${ }^{29}$ who gave the first description of this cortical laminar sclerosis, did not observe an association with Marchiafava-Bignami disease or with chronic liver disease. However, in subsequent reports, ${ }^{28 a}$ comprising 14 cases of cortical laminar sclerosis, the cortical lesion, which is very easily seen, has consistently been associated with a corpus callosum lesion, although the latter may be easily overlooked, as in one of our recovered cases, in which it consisted only of a thin gray line in the genu. It is possible that some of the reported cases of cortical neuronal loss in the chronic alcoholic may be of this type. 


\section{Acquired Hepatocerebral Degeneration}

Yet another secondary dementing syndrome in the chronic alcoholic occurs as part of chronic acquired (non-wilsonian) hepatocerebral degeneration. In a series of 27 such cases, which we collected over a period of several years, ${ }^{30} 20$ of 25 patients in whom mental function could be tested showed varying degrees of dementia. In two of the 25 patients, mental function was intact, and in three others dementia was only suspected, being so mild that we could not be confident of its presence. The patients were ususally alert and the only impairments of consciousness were those associated with episodes of hepatic stupor and coma. Most of the patients were oriented in time and place. In general, the patients were slow in responding and vague in recollecting details of their illness. Notable, also, was their impaired capacity to formulate ideas and to respond to questions logically and relevantly. Attention span was reduced, as was the ability to concentrate on problems and to sustain mental activity of any kind. The patients' fund of recent information was reduced, as was their ability to learn and to retain simple facts. There were no clear-cut instances of agnosia, apraxia, aphasia, or dyscalculia, but several had trouble with tests of these capacities because of inattention. Insight into the deficits was usually lacking.

Formal psychologic testing, using the Wechsler Adult Intelligence Scale and Wechsler Memory Scale, disclosed a partial failure on most of the test items, particularly those measuring visual and verbal abstraction. All of the patients showed an impairment in the acquisition and retention of new information, but in none did these functions appear to be disproportionately affected. Of diagnostic importance was the association of choreoathetosis, dysarthria, cerebellar ataxia, tremors, and, in some, signs of corticospinal disease. In fact, all of the demented patients showed some or all these neurologic abnormalities.

In our patients, alcoholic cirrhosis was only one of several types of liver disease underlying the central nervous system changes. Of course, chronic hepatitis and post necrotic hepatopathy may occur in alcoholic as well as non-alcoholic patients. The cerebral lesions consisted of a patchy necrosis and loss of neurons in all parts of the cerebral cortex (particularly the paretal regions), basal ganglia, and cerebellum, and a characteristic polymicrocavitation of tissue at the cortical-subcortical junction and in the superior pole of the putamen. Typical, also, in the affected areas, were an increase in size and number of protoplasmic astrocytes (type II Alzheimer cells), many of them containing glycogen inclusions, and the presence of abnormal nerve cells, the so-called Opalski cells, which had previously been observed in and thought to be unique to the hereditary (wilsonian) form of hepatolenticular degeneration.

In summary, it is evident, from even this brief review, that a significant deterioration of intellectual or cognitive function (i.e., dementia) can be a manifestation of at least four distinct cerebral diseases that occur commonly in association with chronic alcoholism. Each of these diseases is characterized by a distinctive pathologic change and in each of them (with the possible exception of Marchiafava-Bignami disease) there is an established pathogenesis. It is noteworthy that the lesions, in each of these diseases, are characterized by specificity of localization and symmetry of distribution, marking them as nutritionalmetabolic in nature. In none of these diseases can alcohol be incriminated as a primary cause; indeed, each of them is encountered in clinical circumstances in which alcohol plays no part.

\section{Primary Alcoholic Dementia}

We return now to the question posed in the introductory paragraphs of this article. Is there, in addition to the established types of dementia associated with alcoholism, a persistent dementia in the chronic alcohoic attributable to the direct toxic effects of alcohol on cerebral cortical neurons? As has been indicated, this is a contentious matter, and the evidence that has been put forth in support of this view demands careful examination from several points of view.

\section{Clinical Evidence}

A survey of psychiatric writings on the subject of alcoholic dementia and deteriorated state discloses a remarkable imprecision and lack of uniformity in defining these syndromes. Some of the definitions in early writings have been quoted in the introductory part of this article. A sampling of more modern writings serves to convey the vagueness that still exists about the clinical concept and the diverse and contradictory opinions of what constitutes this syndrome. Chafetz, ${ }^{31}$ for example, in the Comprehensive Textbook of Psychiatry (2nd edition), defines this state as "a gradual disintegration of personality structure, with emotional lability, loss of control and dementia". Lewis ${ }^{32}$ describes patients with this condition as exhibiting "deficiencies of memory and judgment, laziness, indifference, facile euphoria, and lability of mood, with failure to observe responsibilities, mendacity, gross lack of self-control, and general demoralization". To Strecker, Ebaugh, and Ewalt, ${ }^{33}$ who for many years authored a standard textbook of psychiatry, the alcoholic deteriorated state denotes "the common end reaction of all chronic alcoholics who do not recover from their alcoholism or do not die of some accident or intercurrent episode". The case histories presented by the latter authors as examples of the alcohol deteriorated state disclose a striking diversity of clinical manifestations, including jealousy and suspiciousness; blunting of moral fiber and other personality and behavioral disorders; deterioration of work performance, personal care and living habits; disorientation; and impaired judgment and defects of intellectual function, particularly of memory. Bleuler's ${ }^{34}$ description of alcoholic deterioration included the aforementioned features and a number of other behavioral disorders as well: ethical degeneration, dulling of the finer sentiments, brutality of behavior, impulsive actions, ability of affect, diminution of willpower, euphoric attitude, and exaggerated "ego reference". Some authors have even included a variety of physical symptoms in the definition of the alcoholic deteriorated state, such as dilation of facial capillaries, a "bloated look," flabby muscles, chronic gastritis, tremors, recurrent seizures, myocardial changes, cirrhosis, and polyneuropathy. ${ }^{35}$

In the view of Hécaen and De Ajuriaguerra, ${ }^{36}$ alcoholic dementia is distinguished not so much by its symptomatology as by the clinical setting in which it occurs. They write: "As [alcohol] intoxication progresses, intellectual blunting ... characterized by slow mentation, imprecision of thought, defective attention, difficulty with synthesis, fluctuating orientation and impaired judgment, is noted." According to these authors, dementia may be partially reversed by periods of sobriety, only to worsen with subsequent delirious episodes, which, upon their termination, leave an ever-increasing intellectual deficit. 
Certain older authors ${ }^{2,34}$ were impressed with similarities between some of the foregoing symptoms and those of general paresis - hence the term "alcoholic pseudoparesis". Mercifully, the latter terms no longer appears in medical writings. The term alcoholic deteriorated state is often used to describe patients in the chronic, nonconfabulatory stage of the Wernicke-Korsakoff syndrome, in whom the ocular and ataxic signs of Wernicke's disease are no longer evident or had not been observed in the first place.

It is noteworthy that "alcoholic dementia" is no longer listed as a diagnostic category in the current Diagnostic and Statistical Manual of Mental Disorders (DSM-III-R) ${ }^{37}$ Presumably this term, listed in earlier editions of DSM, has been abandoned because its implication - that alcohol per se causes dementia has been difficult to document. Replacing alcoholic dementia in DSM-III-R is the noncommittal diagnostic category "dementia associated with alcoholism", the essential features of which are said to be the persistence of a dementia for longer than three weeks after the cessation of drinking and the exclusion of all possible causative factors other than the prolonged heavy use of alcohol. Diagnosis, then, depends upon purely arbitrary and rather flimsy clinical criteria.

Even more noteworthy is the fact that reference to alcoholic dementia is not to be found in several leading English and American textbooks of psychiatry. In the third edition of the Mayer-Gross Textbook of Clinical Psychiatry, ${ }^{38}$ for example, the term alcoholic dementia (or any of its synonyms) is not mentioned. The same is true of the American Handbook of Psychiatry (see specifically the chapters on alcoholism by Chafetz et al. ${ }^{39}$ and by Mello and Mendelson ${ }^{40}$ ). Lipowski, ${ }^{41}$ writing on the organic mental disorders, lists the terms "alcoholic deterioration" and "dementia associated with alcoholism" in tables reproduced from DSM-II and DSM-III, respectively, but discusses them no further. In the Cambridge edition of The Handbook of Psychiatry, ${ }^{42}$ the notion of alcoholic dementia as a clinical-pathologic entity is pointedly rejected for many of the reasons to be discussed further on.

In recent years, there have been attempts by several authors, notably Cutting, ${ }^{43}$ Seltzer and Sherwin, ${ }^{44}$ Lishman, ${ }^{45,46}$ and Horvath $^{47}$ to reestablished the concept of a primary alcoholic dementia.

Cutting ${ }^{43}$ has used the term "alcoholic dementia" to designate a clinical picture that resembles Korsakoff psychosis but is separable from it on clinical grounds. Cutting's formulation was based on a retrospective survey of the records of 63 alcoholics who had been admitted to the Maudsley Hospital; a label of Korsakoff psychosis had been applied to 50 of these patients, and of alcoholic dementia to 13 others. When the patients designated as Korsakoff psychosis were subdivided into those with relatively acute onset and those with gradual onset, the latter group resembled the patients designated as alcoholic dementia in a number of ways: somewhat greater female preponderance, later age of onset, longer duration of symptoms, poorer performance on a standard intelligence test, and paradoxically, somewhat better prognosis. On the basis of these findings, Cutting, ${ }^{43}$ and also Lishman, ${ }^{46}$ proposed that the term Korsakoff psychosis be limited to patients who conform to the "conventional notion" of the syndrome - i.e., a fairly pure disorder of memory of acute onset - and that patients with symptoms of more global type and more gradual evolution be considered to have alcoholic dementia.
Perhaps this notion of the Korsakoff amnesic syndrome is the conventional one, but if so, it is not consonant with the observed facts, clinical or pathologic. That the Wernicke-Korsakoff syndrome is more common in women has been long recognized..$^{10}$ That the evolution of symptoms is more gradual and the performance on intelligence tests is more impaired in some Korsakovian patients that in others are well-documented variations in the evolution and severity of the disease process. ${ }^{10}$ More importantly, the Korsakoff syndrome in the alcoholic does not necessarily have an acute onset. In our series of pathologically verified cases, ${ }^{10}$ in which the patients were observed from the very inception of the neuropsychiatric illness, the amnesic syndrome evolved in one of several ways: (1) more or less acutely, the intial symptoms being those of a delirium or a quiet confusional state; (2) acutely or subacutely, as part of Wernicke encephalopathy; (3) insidiously, with gradual or intermittent progression and without other neurologic signs. The important point is that the neuropathologic findings proved to be the same, irrespective of the mode of onset of the mental disorder.

Unjustified, also, is the view that Korsakoff psychosis "be regarded as a fairly pure disorder of memory ... and that mental functions other than those directly related to memory remain intact". ${ }^{43}$ Undoubtedly, an impairment of retentive memory is the central feature of Korsakoff psychosis, but patients with this disorder invariably show disturbances of cognitive function that depend little or not at all on memory. Standard psychologic tests (Wechsler Adult Intelligence Scale; Wechsler Memory Scale) consistently disclose defects in tests designed to measure learning ability in a new situation, capacity for concentration, spatial organization, and visual abstraction. ${ }^{48-50}$ (see also ref No. 10. pp $46-50$ and pp 174-191). A wide array of perceptual and conceptual deficits can be demonstrated by special psychologic tests, as Talland's studies of our clinical materials have made clear. ${ }^{51}$ These cognitive abnormalities occur in varying degrees of severity, but the consistency with which they are found, even in the stable phase of the illness, indicates that the cognitive disorder of the Korsakoff syndrome cannot be defined in terms of memory alone. Finally it should be noted that the amnesic syndrome also embodies certain behavioral abnormalities. Typically, the patient is apathetic and inert, uninterested in and indifferent to his surroundings, with little or no insight into his illness. Confabulation may or may not be present, depending largely on how this symptom is defined; it is typically absent in the chronic stable phase of illness, no matter how broad one's definition; in fact, Lewis' definition of alcoholic dementia, quoted earlier, is really an accurate description of the late nonconfabulatory state of Korsakoff psychosis. $^{32}$

In essence then, the Korsakoff syndrome is a form of dementia, i.e., a chronic clinical syndrome that consists of several relatively overlapping intellectual impairments, presenting in a number of different combinations. In the Korsakoff syndrome, failing memory is but one (albeit the most prominent) of several cognitive and behavioral impairments. ${ }^{51 a}$

Seltzer and Sherwin ${ }^{44}$ have approached this problem somewhat differently. They evaluated 80 randomly selected patients in whom the nonspecific diagnosis of "organic psychosis" or "chronic brain syndrome" had been made. In 10 of these patients, a history of alcoholism was coupled with a dementia. In addition to amnesia, the mental state in these 10 alcoholic patients was said to be characterized by a stable course and an 
absence of language abnormality (thus distinguishing it from senile dementia) and by prominent constructional and behavioral disturbances, distinguishing it in their mind from Korsakoff psychosis. Two patients were described in some detail by Seltzer and Sherwin as examples of alcoholic dementia (their cases 4 and 5). The clinical state in one of these patients could be explained by the presence of Korsakoff syndrome in conjunction with the effects of severe cerebral trauma; nor is the clinical picture in the second patient inconsistent with that of Korsakoff psychosis, at least in the view of the present author.

An important feature of the alcoholic Korsakoff syndrome, which has been generally neglected in the writings on alcoholic dementia is the gradually changing character of the mental disorder. In the initial stages of the illness, a global confusional state predominates - i.e., a state characterized by drowsiness, inattentiveness, disorientation, gross misinterpretations of environmental stimuli, and misidentifications of persons. Over a period of several weeks to a month or longer, the confusional symptoms recede and the patient becomes more testable, at which time the defect in retentive memory, often with confabulation, stands out, and the associated cognitive and behavioral disturbances, described above, also become evident. Contrary to common belief, the defects in learning and memory improve slowly, sometimes to a considerable degree. As memory function improves, confabulation tends to drop out of the picture; and in the chronic stable stage of the illness, confabulation is practically always absent. ${ }^{10,51}$ It is manifestly illogical to designate one phase of this mental disorder by one name (Korsakoff psychosis) and the more chronic phase by another (alcoholic dementia or deteriorated state), as though they were different diseases.

We have been impressed by the fact that when patients are seen for the first time in the chronic nonconfabulatory stage of the disease, the connection with the early stages of the Wernicke-Korsakoff syndrome is frequently not recognized. In the course of our studies on alcoholism, we examined a large number of state mental hospital patients who carried the diagnosis of alcoholic dementia or alcoholic deteriorated state. Careful examination of these patients disclosed that more than half of them still had the ocular and/or the cerebellar stigmata of Wernicke disease (fine horizontal nystagmus on lateral gaze, slightly wide-based gait, inability to walk tandem), even though these signs had been overlooked at the time of their admission to the mental hospital.

In summary, an analysis of modern writings on the subject of alcoholic dementia fails to identify a clinical entity, clearly separable from the spectrum of clinical changes that constitute the Korsakoff syndrome in its various stages of evolution and devolution. Remarkable is the fact that in not one of the aforementioned writings that support the notion of an alcoholic dementia, have the clinical observations been subjected to neuropathologic verification.

\section{Psychologic Evidence}

Over the years, there have been numerous attempts to define the impairment of cognitive functions in alcoholics by the use of special psychologic tests. The literature on this subject is far too large to be considered here in any detail. Only the main themes of these writings and their possible relationship to Korsakoff psychosis and alcoholic dementia will be indicated.
A disorder identified by its predominant defect in retentive memory, similar to the one described originally by Korsakoff, has been recognized by all investigators. As pointed out in the preceding section, the Korsakoff syndrome cannot be defined in terms of memory defect alone. Our early studies, ${ }^{48,48 a}$ using standard psychologic tests, consistently demonstrated a characteristic pattern of cognitive defects, mainly in the spheres of spatial organization and verbal and visual abstraction. The occurrence of widespread cognitive deficits in Korsakoff patients, mainly in visuoperceptual and abstracting functions has been confirmed by many investigators, most recently by Jacobson and his colleagues. ${ }^{49,50}$

Less well established is the occurrence of a similar pattern of cognitive impairment (though less in degree) in alcoholics who show no memory defect or other signs of neurologic disease. Wechsler, ${ }^{52}$ in 1941, using his adult intelligence test, found that neurologically-unimpaired alcoholics had a diminished ability to learn new material, to reason abstractly, and to organize complex perceptions. The verbal test scores were found to be superior to the performance test scores, a pattern that Wechsler considered to be a non-specific mark of intellectual deterioration. Kaldegg ${ }^{53}$ and Teicher and Singer ${ }^{54}$ duplicated Wechsler's findings. There followed in the 1970's a series of reports and reviews, ${ }^{55-59}$ all of which purported to show that the capacity for abstract reasoning and the solution of visuo-spatial problems (object assembly, block design, categories test, tactual performance tests, trail making test), and "set persistence and set shifting" were impaired in the chronic alcoholic, whereas verbal skills (vocabulary, information, comprehension, and language) were preserved. Goldstein ${ }^{60}$ also stressed the difference between verbal and long-term memory-dependent abilities on the one hand, and complex abstraction and problem solving abilities on the other.

Ryan et al. ${ }^{61}$ and several other investigators have analyzed the results of psychologic testing in a group of alcoholic subjects who showed a discrepancy in their scores on the Wechsler Adult Intelligence and the Wechsler Memory Scales. A marked discrepancy between these scales marked the disorder as a Korsakoff amnesic syndrome. Among alcoholic subjects without overt manifestations of the Korsakoff syndrome they found a continuum of memory impairment, and this impairment extended even to social drinkers. ${ }^{62}$ Two interpretations were offered: (1) that there is a single alcoholic neuropsychiatric disease, the most advanced form of which is Korsakoff psychosis; and (2) that there are two distinct alcoholic diseases, one being the Korsakoff amnesic syndrome and the other being a more global deterioration of intellect, or alcoholic dementia.

Bowden ${ }^{63}$ had made a strong argument for the first point of view, i.e., that the spectrum of cognitive deficits associated with alcohol abuse reflects the heterogeneous clinical manifestations of the Wernicke-Korsakoff syndrome. Other authors, notably Jacobson and his colleagues, ${ }^{49,50}$ have taken the other point of view. The latter authors assume that the nonamnesic cognitive abnormalities of the Korsakoff syndrome betray the presence of frontal cortical lesions and have suggested, on the basis of this assumption, that the alcoholic Korsakoff syndrome has a dual etiology - (1) thiamine deficiency, which causes the diencephalic lesions (and memory loss); and (2) alcohol toxicity, which is responsible for the frontal cortical lesions (and cognitive loss). These assumptions are contradicted by the pathologic data. In none of our large series of autopsied cases of WernickeKorsakoff disease could we detect morphologic alterations in 
the frontal cortex, even though all of these patients, during life, had displayed characteristic cognitive deficits, and even though some of them had shown a widening of the frontal sulci on gross examination of the brain. ${ }^{10}$

In this regard, it should be noted that cognitive deficits, similar to those of the Korsakoff syndrome, regularly accompany two other amnesic states, namely those that result from lesions of the hippocampus and of the thalamus. (sec reference No. 10, pp 182.185 and pp 189-191) Scrutiny of the brains in such cases has not disclosed any histologic abnormalities of the frontal cortex. Thus it appears that cognitive changes, in at least three types of amnesic syndrome, depend not on a frontal cortical pathology but on the lesions responsible for the amnesia itself.

It is important to point out that the many psychologic studies in which nonkorsakovian alcoholics displayed cognitive abnormalities have been performed in recently abstinent alcoholics (in the first two months of detoxification, as a rule). When similar subjects were examined repeatedly over a period of several months to a year after cessation of drinking, cognitive function was observed to improve gradually, and often completely. ${ }^{64-67}$ The latter observations, of which those of Grant et al. ${ }^{67}$ are the most convincing, discredit the view that the neurotoxic effects of alcohol are responsible for persistent cognitive abnormalities in alcoholic subjects. Also untenable, in the light of these observations, is the oft-repeated view that cognitive impairment in the alcoholic is the result of alcohol-induced premature aging of cerebral neurons. ${ }^{52.68-71}$ The present author would take the position that reversibility of some or all of the psychologic abnormalities in the alcoholic, particularly during the first weeks and months of abstinence, ${ }^{64-67}$ are incompatible with aging changes, which are irreversible. Moreover, although both alcoholics and elderly non-alcoholic subjects show certain psychometric electrophysiologic (evoked potential) abnormalities when compared to young healthy controls, these abnormalities are quite different in the alcoholic and elderly groups, suggesting that they do not have a common mechanism. ${ }^{72}$

\section{Radiologic Evidence}

As has already been mentioned, the crux of the problem with the concept of a primary alcoholic dementia is the uncertainty about an underlying morphologic change. Repeated reference is made to occurrence in alcoholics of "cerebral atrophy", mainly on the basis of certain radiologic findings, particularly enlargement of the lateral ventricles and widening of the cerebral sulci. The relationship of these radiologic abnormalities to dementia or to any other mental disorder in the alcoholic is far from clear. In fact, the common assumption that the radiologic changes represent cerebral atrophy, i.e., a degeneration of cerebral neurons and loss of cerebral substance, needs to be critically examined.

The original concept of an alcoholic cerebral atrophy was essentially a product of pneumoencephalography (PEG). Relatively young alcoholics, some with and some without clinical manifestations of cerebral disease, showed enlarged cerebral ventricles and widened sulci. Beginning with the report of Tumarkin et al., ${ }^{73}$ and extending over the next two decades (the PEG era), large numbers of alcoholics were subjected to air studies. ${ }^{74-88}$ It became apparent that mild to moderate enlargement of the lateral and third ventricles and widening of the cerebral sulci, particularly in the frontal lobes, were common (but far from universal) PEG findings in hospitalized alcoholics. These radiologic abnormalities were indiscriminately referred to as "brain damage" and "cerebral atrophy", although evidence of cerebral atrophy, in the strict pathologic sense, was entirely lacking. Nor could these abnormalities be related to a distinctive clinical syndrome. Enlarged ventricles and widened sulci were observed in some alcoholic patients with neuropsychiatric disturbances, but were found almost as frequently in alcoholics in whom signs of disease were not clinically evident. ${ }^{76,80}$ Furthermore, in symptomatic alcoholics with PEG evidence of "atrophy", no relationship could be discerned between the degree of atrophy and the severity of the neuropsychiatric symptoms. ${ }^{74,78,79,82,83,86,88}$ An early observation of interest went largely unnoticed; in two alcoholics, regression of the PEG abnormalities occurred when alcohol was discontinued. ${ }^{81}$

With the advent of computerized tomography (CT) and magnetic resonance (MR) imaging, large numbers of alcoholic patients were once again examined for the presence of cerebral abnormalities. ${ }^{89-101.101 a}$ These studies yielded much the same information as the earlier air studies. The degree of ventricular and sulcal enlargement seemed to be influenced by the age of the patient, but other meaningful correlations could not be established. Some authors ${ }^{89,92,94,96}$ found a relationship between the severity of the radiologic abnormalities and the duration and intensity of drinking; others ${ }^{102.103}$ could not substantiate such a relationship, once age was partialled out. Again, alcoholics with ventricular and sulcal enlargement (by $\mathrm{CT}$ and $\mathrm{MR}$ ) may or may not show impairment of mental function, ${ }^{91.93}$ and among those with mental impairment there is no consistent relationship between the degree of ventricular and sulcal enlargement and the degree of cognitive abnormality. ${ }^{97}$ In fact, in the series of Epstein et al.,"1 44.4 percent of alcoholics with overt neuropsychiatric symptoms showed no CT abnormalities at all. Similarly, Hill and Mikhael ${ }^{95}$ found many neuropsychologic deficits in abstinent alcoholics even when the CT scans were normal.

The great advantage of CT scans and MRI, of course, is the ease with which they can be repeated. The use of multiple scans, made initially in close relation to withdrawal of alcohol and repeated at later dates, after several weeks or months of abstinence, has made it clear that ventricular enlargement and sulcal widening in these circumstances are potentially reversible, once the patient becomes abstinent. ${ }^{101,102,104,105}$ The largest of these studies is that of Ron and her colleagues. ${ }^{102}$ They examined 100 male alcoholics who had been admitted to an inpatient unit for treatment of alcoholism; in none was there clinical evidence of cerebral damage. Fifty age-matched volunteers who drank little or not at all served as controls. A number of radiologic measurements in these patients - width of cerebral and cerebellar sulci, width of the sylvian and interhemispheric fissures, and size of the venticular system - were significantly greater in the alcoholic group. Fifty-six of the 100 alcoholic patients were reexamined between 30 and 152 weeks (mean 66.3 weeks) after the initial examination; 40 patients had reverted to their previous drinking habits, and their CT abnormalities showed little change. Sixteen patients either remained abstinent during the follow-up period or reduced their drinking to less than four episodes of drinking each lasting less than one week; in this latter group there was a significant diminution in the sulcal and ventricular enlargement. Perhaps, if the period of abstinence had 
been more complete or prolonged, the extent of reversal of the CT changes might have been even more impressive. The MRI studies reported by Zipursky and his colleagues ${ }^{101}$ have shown that significant reversibility of ventricular enlargement occurs within two to four weeks of alcohol withdrawal - a finding that is in keeping with our experience.

Several additional points concerning the CT and MR findings in chronic alcoholics should be emphasized:

1. The ventricular and sulcal enlargement is generally mild to moderate in degree (this was also true of the PEG studies). Only in exceptional instances does the degree of enlargement approach that observed in Alzheimer disease or other bona fide dementias.

2. The radiologic abnormalities, in the form of enlarged ventricles and widened sulci, have been described in many alcoholics in whom there was no clinical evidence of impaired cerebral function. ${ }^{76.102 .103 .106}$ However, when such patients were subjected to formal psychologic testing (Wechsler Adult Intelligence Scale and the Halstead-Reitan Battery), certain defects were elicited and a causal relationship was proposed, namely, that the PEG or CT abnormalities ("brain atrophy") were responsible for the psychometric defects. This proposal is flawed on several counts. As indicated above, some investigators have not found a correlation between the psychometric and radiologic abnormalities ${ }^{98,107}$ Other studies, in which such a relationship is proposed, show serious inconsistencies. Brewer and Perret, ${ }^{76}$ for example, describe five patients with no psychometric abnormalities, yet four of the five showed the radiologic changes of "cerebral atrophy".

Of particular importance in this connection are the investigations of Wilkinson. ${ }^{71,100} \mathrm{He}$ demonstrated that in clinically normal alcoholics, the radiologic measures of "brain atrophy" were agerelated, and that once the age factor was partialled out, the CT findings in these patients did not differ significantly from those of non-alcoholic controls. Not surprisingly, the CT abnormalities in clinically impaired alcoholics (mainly patients with varying degrees of the Wernicke-Korsakoff syndrome) were not age-related.

3. A pathologic basis for the radiologic abnormalities has not been established. Such changes as have been described and alleged to underlie cerebral atrophy in alcoholics are not acceptable, for reasons to be elaborated in the next section.

4. Finally, it is imporant to note that ventricular and sulcal enlargement disclosed by CT scanning and reversibility of these abnormalities are known to occur in a number of other metabolic and nutritional disorders, namely in anorexia nervosa, ${ }^{108,109}$ Cushing syndrome, ${ }^{199}$ kwashiorkor, ${ }^{110}$ and in patients who had been treated for prolonged periods with steroids. ${ }^{11-113}$

The nature of these reversible CT abnormalities is not understood. Perhaps they are due to a slow shift of fluids from brain to CSF spaces and then, as the metabolic disturbance is reversed (improved nutrition, withdrawal of alcohol or corticosteroids), to a shift in the opposite directions. The fact that these changes occur over periods of several weeks or months has prompted the speculation that they depend upon regeneration of cellular proteins or the regrowth of attenuated neuronal processess. ${ }^{114.115}$

In summary, the occurrence of ventricular and sulcal enlargement in alcoholics without clinical evidence of cerebral dysfunction and the potential reversibility of these abnormalities are difficult to reconcile with the concept of cerebral atrophy. The term "atrophy", as conventionally used by neuropathologists, designates a disturbance of neurons that leads to their gradual degeneration and death. To speak of CT abnormalities of the brain and their reversibility as "reversible atrophy" takes unwarranted license with the term and does nothing to enhance our understanding of the process. In the present state of our knowledge it would be preferable to refer to ventricular enlargement and sulcal widening as such, rather than as cerebral atrophy.

\section{Neuropathologic Evidence}

The pathologic changes that purportedly underlie primary alcoholic dementia are even less precisely defined than the clinical syndrome. These changes need to be considered in some detail, since they are referred to repeatedly by psychiatrists and psychologists, who seem to have accepted them, without question, as the basis for a variety of cognitive and behavioral disorders in the alcoholic.

Courville, " whose writings have been quoted most frequently in this respect, enumerated the following changes as being characteristic of alcoholic dementia: progressive atrophy of the cortex of the frontal lobes, particularly the convolutions of the dorsolateral surface, associated with opacity and thickening of the overlying meninges and enlargement of the anterior horns of the lateral ventricles; swelling, pyknosis, and pigmentary atrophy of nerve cells; irregular loss of medium-sized pyramidal cells of the superficial and intermediate cortical laminae; and secondary degeneration and loss of nerve fibers, particularly the radiating fibers of the convolutional gray matter. These changes were attributed by Courville to the chronic toxic effects of alcohol. Parenthetically it should be noted that the very same pathologic changes were said by Courville to underlie delirium tremens." We have not observed these or any other significant histologic abnormalities in a large number of patients who died in delirium tremens (which is what one would expect in a potentially reversible disease), or in the frontal cortex in cases of WernickeKorsakoff disease.

The neuropathologic changes described by Courville and his interpretation of these changes are simply not acceptable, despite their widespread and uncritical acceptance by non-neuropathologists. Some of these changes are quite nonspecific and of questionable significance. Opacity of the meninges and mild to moderate dilatation of the lateral ventricles, for example, are ubiquitous neuropathologic findings; they are observed in alcoholics and non-alcoholics alike and in persons with a diversity of morbid states, as well as in those who had betrayed no neurologic or psychiatric abnormalities during life. Much the same can be said about so-called pigmentary atrophy, i.e., the accumulation of lipofuscin, mainly in neurons but also in astrocytes. This pigmentary accumulation is observed to some extent in practically all adult brains and becomes more prominent with aging; it is a prominent finding in virtually all diseases of the central nervous system. Some of the nerve cell changes described by Courville, allegedly indicative of neuronal degeneration, are nothing more than artifacts due to the improper handling, fixation, and staining of tissue. The patchy loss of nerve cells and degeneration of the radiating fibers in the intermediate laminae of the cerebral cortex may have been due to anoxia; such changes are also characteristic of chronic hepatocerebral degeneration and Marchiafava-Bignami disease. Interestingly, 
Courville himself, in some of his other writings, ${ }^{116,117}$ had described such changes in patients with anoxic encephalopathy. In alcoholics, however, he chose to attribute these changes not to anoxia, but to some ill-defined vasomotor changes induced by alcohol.

Courville's study," comprising 123 cases, is open to criticism on other grounds as well. How his cases were chosen is not described except to state that "attention was directed to those cases having a history of neurological or psychiatric manifestations of alcoholism (hospital cases) or in whom the problem of alcoholism appeared to be an important feature from a medicolegal aspect (coroner's cases)". Aside from this statement, Courville provided no clinical descriptions of the patients whose brains were being examined. One has no way of relating the pathologic findings to any particular clinical syndrome, except by referring to the chapter headings, e.g. "delirium tremens" or "alcoholic deteriorated state". Control observations in neurologically intact alcoholics or in non-alcoholics are not mentioned.

Much of the criticism of Courville's work is applicable also to that of Lynch, ${ }^{118}$ Miyakawa et al., ${ }^{119}$ and Stevenson, ${ }^{120}$ authors that are being quoted to the present day as having described the pathologic changes of alcohol dementia. Lynch ${ }^{118}$ described the brain lesions of 11 alcoholics, five of whom died in delirium tremens and three from bleeding esophageal varices. One of the patients had cirrhosis of the liver, but no other clinical data are given. Remarkably, the only area of cerebral cortex studied in each of Lynch's cases was one portion of the Rolandic gyrus. A patchy loss of cortical nerve cells and fibers is illustrated; again, these were possibly due to anoxia or chronic hepatocerebral degeneration, or to some other disease process. Lynch attributed these lesions to such unverified pathogenetic factors as "interference with capillary blood supply" and "repeated episodes of hepatogenic fat embolism".

Miyakawa et al. ${ }^{119}$ described several histologic abnormalities in the brains of "six habitual and heavy drunkards". Three of these patients carried the clinical diagnosis of Wernicke disease and another of Korsakoff psychosis; in the remaining two patients (as well as in those with the Wernicke-Korsakoff syndrome), a character change, consisting of aggressivity, irritability, and apathy was said to have been present. In addition to lesions consistent with the Wernicke-Korsakoff syndrome, the authors described a widespread patchy loss of nerve cells, most prominent in layers III and IV of the frontal and temoral cortices. The illustrations of these changes are unconvincing. Possibly they represent the terminal effects of anoxia or some other process, although the authors ${ }^{119}$ chose to attribute them to the toxic effects of alcohol. The clinical status of the patients (except for the statement that Wernicke-Korsakoff disease was present) was insufficiently described to allow for any meaningful clinicopathologic correlations.

Stevenson ${ }^{120}$ also described a number of nonspecific neuropathologic changes in patients dying of a variety of conditions that had been attributed during life to alcoholism ("alcoholic encephalopathy", "psychosis with somatic disease", "unclassified psychosis due to alcohol","acute and chronic alcoholism"). Stevenson was of the opinion that whatever changes were responsible for the clinical picture and death of these patients could not be demonstrated histologically. The writings of Warner $^{121}$ and of Okhuma ${ }^{122}$ are so uncritical that they do not merit further consideration.
During the past 15 years the neuropathologic effects of alcohol on the brain have been studied by a variety of techniques. These studies are briefly reviewed below. None of the newer studies, like the older ones, have provided convincing evidence that alcohol alone produces irreversible structural alterations in the brain.

Harper and his colleagues ${ }^{123,124}$ reported that in a group of alcoholics the mean brain weight decreased and the peri-cerebral space was increased, when compared to a group of nonalcoholic control subjects. Such findings do no more than confirm the shrinkage of brain that is demonstrable in many alcoholics by $C T$ scans and MRI and is reversible with sustained abstinence. Other investigators have not duplicated these findings. In a series of alcoholics who were studied at the Massachusetts General Hospital, brain weights did not differ significantly from those of non-alcoholic controls (de la Monte ${ }^{125}$ ). Also no reduction in brain weight was demonstrated in dogs that had received 36 percent of their calories as ethyl alcohol for one year. ${ }^{126}$

Harper and colleagues, ${ }^{127}$ using an automated cell counting method, reported a reduction in the number of neurons in the superior frontal cortex of chronic alcoholics. However, their study did not include editing of the video image, an essential part of the morphometric study of cerebral cortex by automated image analysis (see Terry and DeTeresa ${ }^{128}$ ). In fact, using this technique (with video editing), Hansen et al. ${ }^{126}$ could demonstrate no reduction in the neocortical neuronal populations of severely alcoholic dogs. ${ }^{126}$ The small, dark neurons described by Harper et al. ${ }^{127}$ and attributed by them to the neurotoxic effects of alcohol do not represent a meaningful neuropathologic change.

Nor have other experimental studies settled the problem. The protracted ingestion of alcohol in mice and rats has been reported to cause a partial loss of cells in the hippocampal and dentate gyri. ${ }^{129.130}$ An immense amount of alcohol was required to produce these changes (corresponding, in a 70 kilo man, to about 100 ounces of 86 proof whiskey daily for 10 years). On the other hand, Phillips et al. ${ }^{131}$ have demonstrated that cerebral cortical neurons of rats are remarkably resistant to the direct topical application of alcohol; these neurons showed no signs of degeneration even after the cortex was superfused by a concentration of ethanol three times greater than the concentration of alcohol that caused death in the rat by paralysis of the respiratory center.

\section{Concluding Remarks}

The foregoing remarks are not intended to convey the notion that all cases of so-called alcoholic dementia are examples of the Korsakoff syndrome in one form or another, an issue that has appropriately been raised by Horvath ${ }^{47}$ and by Bowden. ${ }^{63}$ Nevertheless, in our experience, the large majority of patients who have come to autopsy with the clinical diagnosis of primary alcoholic dementia or alcoholic deteriorated state have shown the lesions of the Wernicke-Korsakoff syndrome, the clinical features of which had not been recognized during life. Traumatic lesions of varying type and degree of severity were sometimes added. Isolated cases, a few with and others without the Wernicke-Korsakoff lesions, have shown the lesions of anoxic encephalopathy, acute and chronic hepatic encephalopathy, 
communicating hydrocephalus, Alzheimer disease, Marchiafava-Bignami disease, ischemic infarction, or some other disease quite unrelated to alcoholism. Practically always, in our material, the clinical state could be accounted for by one or a combination of these disease processes, and there has been no need to invoke a separate entity due to the toxic effect of alcohol on the brain.

The experience of Torvik and his colleagues, ${ }^{132}$ based on an extensive autopsy material (711 cases of suspected or proven alcoholism) has been similar to our own. With the exception of a few coincidental conditions, such as Alzheimer disease and cerebral infarction, all alcoholics that had been labelled as alcoholic dementia turned out to have inactive (chronic) WernickeKorsakoff disease. They found no cases of dementia that could be attributed to "brain atrophy" alone.

The most serious flaw in the concept of a nonkorsakovian alcoholic dementia is that it lacks a distinctive, well-defined pathology. The nature of the sulcal widening and the ventricular enlargement in young alcoholics has never been established; their inconstant association with neuropsychiatric symptoms and their reversibility with abstinence do not favor a structural lesion. Perhaps light-microscopic methods are inadequate to disclose the lesions. Sufficiently accurate morphometric and other quantitative techniques have yet to be systematically applied to the study of this problem in man. Until this is done, the possibility of there being a structural basis for these radiologic changes cannot be dismissed with finality. By the same token, the concept of a primary alcoholic dementia must remain ambiguous until such time as its morphologic basis is established.

\section{REFERENCES}

1. Maudsley $\mathbf{H}$. The Pathology of Mind, 3rd ed., London: Macmillan, 1879: 486.

2. Lawson R. On the symptomatology of alcoholic brain disorders. Brain 1878; 1: 182 .

3. Bevan Lewis W. A Textbook of Mental Diseases. London: Charles Griffin and Co., 1889: 346.

4. Wernicke C. Lehrbuch der Gehirnkrankheiten für Ärzte und Studierende, vol. 2, Kassel, Theodor Fischer, 1881, 229-242.

5. Victor M, Yakovlev PI. SS Korsakoff's psychic disorder in conjunction with peripheral neuritis: a translation of Korsakoff's original article with brief comments on the author and his contribution to clinical medicine. Neurology $1955 ; 5: 394-406$

6. Murawieff $W$. Zwei fälle von polioencephalitis acuta haemorrhagica superior (Wernicke). Neurol Zentralbl 1897; 16: 56-61, 106-115.

7. Bonhoeffer K. Der Korsakowsche Symptomenkomplex in seinen beziehungen zu den verschiedenen Krankheitsformen. Allg Z Psychiatr Ihre Grenzgeb 1904; 61: 744-752.

8. Gamper E. Zur Frage der polioencephalitis haemorrhagica der chronischen Alkoholiker: Anatomische Befund beim alkoholischen Korsakow und ihre beziehungen zum klinischen Bild. Dtsch Z Nervenheilkd 1928; 102: 122-129.

9. Malamud W., Skillicorn SA. Relationship between Wernicke and Korsakoff syndrome. Arch Neurol Psychiatry 1956; 76: 585596.

10. Victor M, Adams RD, Collins GH. The Wernicke-Korsakoff Syndrome. A Clinical and Pathological Study of 245 Patients, 82 with Postmortem Examinations. Philadelphia: FA Davis, 1971 (2nd ed., revised, 1989).

11. Courville CB. Effects of Alcohol on the Nervous System of Man. Los Angeles: San Lucas Press, 1955.

12. Carmichael EA, Stern RO. Korsakoff syndrome: its histopathology. Brain 1931; 54: 189-213.

13. Ishii N., Nishihara Y. Pellagra among chronic alcoholics: clinical and pathological study of 20 necropsy cases. J Neurol Neurosurg Psychiatry 1981; 44: 209-215.
14. Serdaru M, Hausser-Hauw C, Laplane D, et al. The clinical spectrum of alcoholic pellagra encephalopathy. Brain 1988; 111 : 829-842.

15. Shah DR, Singh SV, Jain IL. Neurological manifestations in pellagra. J Assoc Physicians India 1971; 19: 443-446.

16. Spivak JL, Jackson DL. Pellagra: an analysis of 18 patients and a review of the literature. Johns Hopkins Med J 1977; 140: 295309.

16a. Bomb BS, Bedi HK, Bhatnagar K. Post-ischaemic paresthesiae in pellagrins. J Neurol Neurosurg Psychiatry 1977; 40: 265-267.

17. Spies TD, DeWolfe HF. Observation on etiological relationship of severe alcoholism to pellagra. Am J Med Sci 1933; 186: 521 532.

18. Goldsmith GA, Sarrett HP, Register UD, Gibbens J. Studies of niacin requirement in man: experimental pellagra in subjects on corn diets low in niacin and tryptophan. J Clin Invest 1952; 31 : 533-542.

19. Victor $M$, Adams RD. Neuropathology of experimental vitamin $\mathrm{B}_{6}$ deficiency in monkeys. Am J Clin Nutr 1956; 4: 346-353.

20. Vilter RW, Mueller JF, Glazer HS, et al. The effect of vitamin $B$ deficiency induced by desoxypyridoxine in human beings. $\hat{j}$ Lab Clin Med 1953; 42: 335-357.

21. Still CS. Nicotinic acid and nicotinamide deficiency: pellagra and related disorders of the nervous system. In: Vinken PJ, Bruyn G, eds. Handbook of Clinical Neurology, vol. 28, Metabolic and Deficiency Diseases of the Nervous System, Part II. Amsterdam: North-Holland Publishing Co., 1976: 59-104.

22. Jolliffe N, Bowman KM, Rosenblum LA, Fein HD. Nicotinic acid deficiency encephalopathy. JAMA 1940; 114: 307-3!2.

23. Cleckley HM, Sydenstricker VP, Geeslin LE. Nicotinic acid in the treatment of atypical psychotic states associated with malnutrition. J Am Med Assoc 1939; 112: 2107-2110.

24. Spillane JD. Nutritional Disorders of the Nervous System. Baltimore: William and Wilkins, 1947: 96-102.

25. Meyer A. On parenchymatous systemic degenerations mainly in the central nervous system. Brain 1901; 24: 47-115.

26. Marchiafava E, Bignami A. Sopra un alterazione del corpo calloso osservata in soggetti alcoolisti. Riv Patol Nerv Ment 1903; 8: 544-549.

27. Castaigne PJ, Buge A, Cambier R, Rancurel G. La maladie de Marchiafava-Bignami: étude anatomo-clinique de dix observations. Rev Neurol 1971; 125: 179-196.

28. Jéquier M, Wildi E. Le syndrome de Marchiafava-Bignami. Schweiz Arch Neurol Neurochir Psychiatr 1956; 77: 393-415.

28a. Delay J, Brion S, Escourelle R, Sanchez A. Rapports entre la dégénérescence du corps calleux de Marchiafava-Bignami et la sclérose laminaire corticale de Morel. Encéphale 1959; 48: 281312.

29. Morel F. Une forme anatomoclinique particulière de l'alcoholisme chronique cliniquement rappelant la pseudo-paralysie des anciens auteurs, anatomiquement présentant une sclérose corticale laminaire. Schweiz Arch Neurol Psychiatr 1939; 44: 305308.

30. Victor $M$, Adams RD, Cole $M$. The acquired (non-wilsonian) type of chronic hepatocerebral degeneration. Medicine 1965; 44: 345-395.

31. Chafetz ME. Alcoholism and alcoholic psychoses. In: Freeman AM, Kaplan HI, Sadock BJ, eds. Comprehensive Textbook of Psychiatry, 2nd ed. Baltimore: Williams and Wilkins, 1975: 1331-1348

32. Lewis A. Psychoses-alcoholic psychoses. In: British Encyclopaedia of Medical Practice, 2nd ed., vol. 10, London: Butterworth and Co., 1952: 394-402.

33. Strecker EA, Ebaugh FG, Ewalt JR. Practical Clinical Psychiatry. Philadelphia: The Blakiston Co., 1951: 155-169.

34. Bleuler EP. Textbook of Psychiatry (authorized English edition, A.A. Brill). New York: MacMillan Co., 1924: 350.

35. Keller M, McCormick M, Efron V. A Dictionary of Words About Alcohol, 2nd ed. New Brunswick, NJ: Rutgers Center of Alcohol Studies, 1982: 90-94.

36. Hécaen $\mathrm{H}$, De Ajuriaguerra J. Les encéphalopathies alcooliques subaigues et chroniques. Rev Neurol 1956; 94: 528-555. 
37. Diagnostic and Statistical Manual of Mental Disorders (DSM-IIIR), 3rd ed, revised. Washington, DC: American Psychiatric Association, 1987

38. Mayer-Gross W, Slater E, Roth M. Clinical Psychiatry, 3rd ed. Baltimore: Williams and Wilkins, 1969: 399-413.

39. Chafetz ME, Hertzman M, Berenson D. Alcoholism: a positive view. In: Arieti $\mathrm{S}$, ed. American Handbook of Psychiatry, 2nd ed., vol. III, New York: Basic Books, 1974: 367-392.

40. Mello NK, Mendelson JH. Alcoholism: a behavioral disorder. In: Arieti S, ed. American Handbook of Psychiatry, 2nd ed., vol. IV. New York: Basic Books, 1975: 371-403.

41. Lipowski ZJ. Organic mental disorders. In: Kaplan HI, Freedman AM, Sadock BJ, eds. Comprehensive Textbook of Psychiatry, 3rd ed. Baltimore: Williams and Wilkins, 1980: 1359-1392.

42. Victor M. Mental disorders due to alcoholism. Chapter 14 In: Lader $\mathrm{MH}$, ed. Handbook of Psychiatry, vol. 2, Mental Disorders and Somatic Illness. Cambridge: Cambridge University Press; 1983: 189-211.

43. Cutting J. The relationship between Korsakov's syndrome and "alcoholic dementia". Br J Psychiatry 1978; 132: 240-251.

44. Seltzer B, Sherwin I. "Organic brain syndromes": an empirical study and critical review. Am J Psychiatry 1978; 135: 13-21.

45. Lishman WA. Alcohol and the brain. Br J Psychiatry 1990; 156: 635.

46. Lishman WA. Cerebral disorder in alcoholism. Syndromes of impairment. Brain 1981; 104: 1.

47. Horvath TB. Clinical spectrum and epidemiological features of alcoholic dementia. In: Rankin JG, ed. Alcohol, Drugs and Brain Damage. Toronto: Alcoholism and Drug Addiction Research Foundation of Ontario, 1975: 1-16.

48. Victor M, Herman K, White EE. A psychological study of the Wernicke-Korsakoff syndrome: results of Wechsler-Bellevue Intelligence Scale and Wechsler Memory Scale testing at different stages in the disease. Q J Stud Alcohol 1959; 20: 467-479.

48a. Victor M, Talland GA, Adams RD. Psychological studies of Korsakoff's psychosis: I. General intellectual functions. J Nerv Ment Dis 1959; 128: 528-537.

49. Jacobson RR, Lishman WA. Selective memory loss and global intellectual deficits in alcoholic Korsakoff's syndrome. Psychol Med 1987; 17: 649-655.

50. Jacobson RR, Acker CF, Lishman WA. Patterns of neuropsychological deficit in alcoholic Korsakoff's syndrome. Psychol Med 1990; 20: 321-334.

51. Talland GA. Deranged Memory. New York: Academic Press, 1965.

51a. Adams RD, Victor M. Principles of Neurology, 5th ed. New York: McGraw Hill, 1993: 364-373.

52. Wechsler D. The effect of alcohol on mental activity. Q J Stud Alcohol 1941; 2: 479-485.

53. Kaldegg A. Psychological observation in a group of alcoholic patients with an analysis of Rorschach, Wechsler-Bellevue and Bender Gestalt test results. Q J Stud Alcohol 1956; 17: 608618.

54. Teicher MI, Singer EA. A report on the use of Wechsler-Bellevue scales in an overseas general hospital. Am J Psychiatry 1946; 103: $91-93$

55. Jones BM. Verbal and spatial intelligence in short- and long-term alcoholics. J Nerv Ment Dis 1971; 153: 292-297.

56. Jones BM, Parsons OA. Impaired abstracting ability in chronic alcoholics. Arch Gen Psychiatry 1971; 24: 71-75.

57. Kleinknecht RA, Goldstein SG. Neuropsychological deficits associated with alcoholism - a review and discussion. Q J Stud Alcohol 1972; 33: 999-1020.

58. Tarter RE. Psychological deficit in chronic alcoholics: a review. Int J Addict 1975; 10: 327-368.

59. Tarter RE, Parsons OA. Conceptual shifting in chronic alcoholics. In: J Abnor Psychol 1971; 77: 71-75.

60. Goldstein G, Perceptual and cognitive deficit in alcoholics. In:Goldstein G, Neuringer C, eds. Empirical Studies of Alcoholism. Cambridge, MA: Ballinger, 1976.
61. Ryan C, Butters N, Montgomery K. Memory deficits in chronic alcoholics: continuities between the "intact" alcoholic and the alcoholic Korsakoff patient. In: Begleiter H, ed. Biological Effects of Alcohol. New York: Plenum Press, 1980: 701-718.

62. Parker ES, Noble EP. Alcohol consumption and cognitive functioning in social drinkers. Q J Stud Alcohol 1977; 38: 12241232.

63. Bowden SC. Separating cognitive impairment in neurologically asymptomatic alcoholism from Wernicke-Korsakoff syndrome: is the neurophysiological distinction justified? Psychol Bull 1990; 107: 355-366.

64. Clarke J, Haughton H. A study of intellectual impairment and recovery rates in heavy drinkers in Ireland. Br J Psychiatry 1975; 126: 178-184.

65. Goldman MS, Rosenbaum GC. Psychological recoverability following chronic alcohol abuse. In: Seixas FA, ed. Currents in Alcoholism, vol II, New York: Grune and Stratton, 1977.

66 Page RD, Linden JD. "Reversible" organic brain syndrome in alcoholics, a psychometric evaluation. Q J Stud Alcohol 1974; 35: 98-107.

67. Grant I, Adams KM, Reed R. Aging, abstinence, and medical risk factors in the prediction of neuropsychologic deficit among long-term alcoholics. Arch Gen Psychiatry 1984; 41: 710-718.

68. Blusewicz MJ, Schenkenberg T, Dustman RE, Beck EC. WAIS performance in young normal, young alcoholic, and elderly normal groups: an evaluation of organicity and mental aging indices. J Clin Psychol 1977; 33: 1149-1153.

69. Goodwin DW, Hill SY. Chronic effects of alcohol and other psychoactive drugs on intellect, learning and memory. $I n$ : Rankin JG, ed. Alcohol, Drugs and Brain Damage. Toronto: Addiction Research Foundation, 1975: 55-69.

70. Schau EJ, O'Leary MR. Adaptive abilities of hospitalized alcoholics and matched controls: the brain age quotient. J Stud Alcohol 1977; 38: 403-409.

71. Wilkinson DA. Accelerated mental aging in alcoholism: working hypothesis or uncontrolled variable? In: Wilkinson DA, ed. Cerebral Defects in Alcoholism. Toronto: Addiction Research Foundation, 1982: 61-77.

72. Porjesz B, Beleiter H. Evoked brain potential differentiation between geriatric subjects and chronic alcoholics with brain dysfunction. In: Courjon J., Mauguiere F., Revol M., eds. Clinical Applications of Evoked Potentials in Neurology. New York: Raven Press, 1982: 117-124.

73. Tumarkin B, Wilson JD, Snyder G. Cerebral atrophy due to alcoholism in young adults. U.S. Armed Forces Med J 1955; 5: 6774.

74. Ballif L, Moscovici M, Banu T, Voicu T. Relatiile dintre manifestarile clinice din alcoolismul cronic si imaginea pneumoencefalografica. Neurol Psihiatr Neurochir 1961; 6: 481-488.

75. Barini O, Silva CP. Atrofias cerebrais em alcoolatras cronicos: estudo pneumencefalografico. Arch Neuropsiquiatr (San Paulo) 1959; 17: 427-430.

76. Brewer C, Perrett L. Brain damage due to alcohol consumption: an airencephalographic, psychometric and electroencephalographic study. Br J Addict 1971; 66: 170-182.

77. Carlsson C, Claeson L-E, Karlsson K-I, Pettersson L-E. Clinical, psychometric and radiologic signs of brain damage in chronic alcoholism. Acta Neurol Scand 1979; 60: 85-92.

78. Giove C, Viani E. Atrofie cerebrali negli etilisti cronici considerazioni fisiopatogeniche e correlazioni dei dati clinici, electroencefalografici, gammaencefalografici e pneumoencefalografici. Neuropsychiatria $1965 ; 31: 548-569$.

79. Grahmann H, Neumann H. Pneumoencephalographische Untersuchungen an Trinkern. Arch Psychiatr Nervenkr 1962; 203: 178-184.

80. Haug JO. Pneumoencephalographic evidence of brain damage in chronic alcoholics: a preliminary report. In: Retterstol N., Magnussen F., eds. Report on the Fifteenth Congress of Scandinavian Psychiatrists in Geilo, Norway, 1967. Acta Psychiatr Scan 203 (Suppl), 1968.

81. Kircher J-P, Pierson C-A. Les atrophies cérébrales dans les toxicomanies: role de la pneumoencéphalographie. Essais thérapeutiques. Maroc Méd 1956; 35: 668-670. 
82. Ledesma Jimeno A. Estudios pneumoencefalograficos en el alcoholismo. Rev Clin Esp 1958; 68: 161-171.

83. Léreboullet J, Pluvinage R. L'atrophic cérébrale des alcooliques; ces conséquences médico-sociales. Bull Acad Nat Med 1956; 140: $398-401$.

84. Leuchs K. Der cerebrale Alkoholschaden im Pneumencephalogramm. Zentralbl Gesamte Neurol Psychiatrie 1958; 148: 5-6.

85. Maller O, Mihailesco N, Paraskivesco E, Elias S. Les modifications cérébrales dans l'alcoolisme chronique. Confin Neurol 1960; 20: 18-26

86. Péron N, Gayno M. Atrophie cérébrales des éthyliques. Rev Neurol 1956; 94: 621-624.

87. Pluvinage R. Les atrophies cérébrales des alcooliques. Bull Soc Méd Hôp (Paris) 1954; 70: 524-526.

88. Postel J, Cossa P. L'atrophie cérébrale des alcooliques chroniques Étude pneumoencéphalographique. Rev Neurol 1956; 94: 604606.

89. Cala LA, Jones B, Mastaglia FL, Wiley B. Brain atrophy and intellectual impairment in heavy drinkers - a clinical, psychometric and computerized tomography study. Aust $\mathrm{N} \mathrm{Z} \mathrm{J} \mathrm{Med}$ 1978; 8: 147-153.

90. Cala LA, Mastaglia FL. Computerized axial tomography in the detection of brain damage. Med J Aust 1980;2: 193-198.

91. Epstein PS, Pisani VD, Fawcett JA. Alcoholism and cerebral atrophy. Alcohol Clin Exp Res 1977; 1: 61-65.

92. Fine EW, Richman SA, Wasserman TW. Relationships between duration and severity of alcohol dependency and damage to the brain (abst). Alcohol Clin Exp Res 1981; 5: 148.

93. Fox JH, Ramsey RG, Huckman MS, Proske AE. Cerebral ventricular enlargement: chronic alcoholics examined by computerized tomography. J Am Med Assoc 1976; 236: 365-368.

94. Götze P, Kühne D, Hansen J, Knipp HP. Hirnatrophische Veränderungen bei chronischem Alkoholismus: eine klinische und computer-tomographische Studie. Arch Psychiatr Nervenkr 1978; 226: 137-156.

95. Hill SY, Mikhael MA. Computed tomography scans of alcoholics: cerebral atrophy? Science 1979; 204: 1237-1238

96. Kroll P, Seigel R, O'Neill B, Edwards RP. Cerebral cortical atrophy in alcoholic men. J Clin Psychiatry 1980; 41: 417-421.

97. Lee K, Moller L, Hardt F, Haubek A, Jensen E. Alcohol-induced brain damage and liver damage in young males. Lancet 1979; 2 : 759-762.

98. Lusins J, Zimberg S, Smokler H, Gurley K. Alcoholism and cerebral atrophy: a study of 50 patients with CT scan and psychologic testing. Alcohol Clin Exp Res 1980; 4: 406-411.

99. Von Gall M, Becker H, Artmann H, et al. Results of compute tomography on chronic alcoholics. Neuroradiology 1978; 16: 329-331.

100. Wilkinson DA. Examination of alcoholics by computed tomographic (CT) scans: a critical review. Alcohol Clin Exp Res 1982; 6: $31-45$

101. Zipursky RB, Lim KC, Pfefferbaum A. MRI study of brain changes with short-term abstinence from alcohol. Alcohol Clin Exp Res 1989; 13:664-666

101a. Sarabia F, Bowden CL. Computerized tomographic evidence of cerebral atrophy in heavy drinkers. South Med J 1980; 73: 716 718

102. Ron MA, Acker W, Shaw GH, Lishman WA. Computerized tomography of the brain in chronic alcoholism. A survey and follow-up study. Brain 1982; 105: 497-514.

103. Wilkinson DA, Carlen PL. Relation of neuropsychological test performance in alcoholics to brain morphology measured by computed tomography. In: Begleiter $\mathrm{H}$, ed. Biological Effects of Alcohol. New York: Plenum, 1980: 683-699.

104. Artmann H, Gall MV, Hacker H, Herrlich J. Reversible enlargement of cerebral spinal fluid spaces in chronic alcoholics. Am J Neuroradiol 1981;2: 23-27.

105. Carlen PL, Wortzman G, Holgate RC, et al. Reversible cerebra atrophy in recently abstinent chronic alcoholics measured by computed tomography scans. Science 1978; 200: 1076-1078.

106. Wilkinson DA, Carlen PL. Neuropsychological and neurological assessment of chronic alcoholism: discrimination between groups of alcoholic subjects. J Stud Alcohol 1980; 41: 129-139.
107. Hill SY, Mikhael MA. Computerized transaxial tomographic and neuropsychological evaluations in chronic alcoholics and heroin abusers. Am J Psychiatry 1979; 136: 598-602.

108. Enzmann DR, Lane B. Cranial computed tomography findings in anorexia nervosa. J Comput Assist Tomogr 1977; 1: 410-414.

109. Heinz ER, Martinez J, Haenggeli A. Reversibility of cerebral atrophy in anorexia nervosa and Cushing's syndrome. J Comput Assist Tomogr 1977; 1: 415-418.

110. Dublin AB, Dublin WA. Cerebral pseudoatrophy and computed tomography: two illustrative case reports. Surg Neurol 1978 10: 209-212

111. Bentson J, Reza M, Winter J, Wilson G. Steroids and apparent cerebral atrophy on computed tomography scans. J Comput Assist Tomogr 1978; 2: 16-23.

112. Langenstein I, Willig RP, Kühne D. Reversible cerebral atrophy caused by corticotrophin. Lancet 1979; 1: 1246-1247.

113. Okuno $T$, Ito $M$, Konishi $Y$, et al. Cerebral atrophy following ACTH therapy. J Comput Assist Tomogr 1980; 4: 20-23.

114. Carlen PL, Wilkinson DA. Alcoholic brain damage and reversible deficits. In: Idestrom C-M, ed. Alcohol and Brain Research. Proceedings, Second Magnus Huss Symposium, September 5-8, 1979. Acta Psychiatr Scand 286 (Suppl) 1980: 103.

115. Harper CG, Corbett D. Changes in the basal dendrites of cortical pyramidal cells from alcoholic patients - a quantitative Golgi study. J Neurol Neurosurg Psychiatry 1990; 53: 856-861.

116. Courville CB. Contributions to the Study of Cerebral Anoxia: Some Observations on its History, its Pathogenesis and Structural Characteristics, the Importance of its Circulatory Component and its Significance in the Evaluation of Certain Chronic Diseases of the Brain of Infancy and Early Childhood. Los Angeles: San Lucas Press, 1953.

117. Courville CB. Case studies in cerebral anoxia. VI. Typical anoxic alterations in the cerebral gray matter after over-dosage of barbiturates. Bull Los Angeles Neurol Soc 1955; 20: 16-24.

118. Lynch MJG. Brain lesions in chronic alcoholism. Arch Pathol 1960; 69: 342-353.

119. Miyakawa T, Hattori E, Shikai I, et al. Histopathological changes of chronic alcoholism. Folia Psychiatry Neurol Jpn 1977; 31: 253-261.

120. Stevenson LD. A study of the changes in the brain in alcoholism. Arch Pathol 1940; 30: 642-645.

121. Warner FJ. The brain changes in chronic alcoholism and Korskov's psychosis. J Nerv Ment Dis 1934; 80: 629-644.

122. Ohkuma T. Zur pathologischen anatomie des chronischen alkoholismus. Z Gesamte Neurol Psychiatr 1930; 126: 94-128.

123. Harper CG, Blumbergs PC. Brain weights in alcoholics. J Neurol Neurosurg Psychiatry 1982; 45: 838-840.

124. Harper CG, Kril J. Brain atrophy in chronic alcoholic patients: a quantitative pathological study. J Neurol Neurosurg Psychiatry 1985; 48: $211-217$

125. de la Monte SM. Disproportionate atrophy of cerebral white matter in chronic alcoholics. Arch Neurol 1988; 45: 990-992.

126. Hansen LA. Natelson BH, Lemere $C$, et al. Alcohol-induced brain changes in dogs. Arch Neurol 1991;48: 939-942.

127. Harper CG, Kril J, Daly J. Are we drinking our neurones away? Brit Med J 1987; 294: 534-536.

128. Terry RD, DeTeresa $R$. The importance of videoediting in automated image analysis in studies of the cerebral cortex. J Neurol Sci 1981; 53: 413-421.

129. Riley JN, Walker DW. Morphological alterations in hippocampus after long-term alcohol consumption in mice. Science 1978; 201: 646-648

130. Walker DW, Hunter BE, Abraham WC. Neuroanatomical and functional deficits subsequent to chronic ethanol administration in animals. Alcohol Clin Exp Res 1981; 5: 267-282.

131. Phillips SC, Cragg BG, Singh SC. The short-term toxicity of ethanol to neurons in rat cerebral cortex tested by topical application in vivo, and a note on a problem in estimating ethanol concentrations in tissue. J Neurol Sci $1981 ; 49: 353-361$.

132. Torvik A, Lindboe CE, Rodge S. Brain lesions in alcoholics: a neuropathological study and clinical correlations. J Neurol Sci 1982; 56: 233-248. 